\title{
Characteristics and operative outcomes for children undergoing repair of truncus arteriosus: A contemporary multicenter analysis
}

Christopher W. Mastropietro, MD, FCCM, ${ }^{\mathrm{a}}$ Venu Amula, MD, ${ }^{\mathrm{b}}$ Peter Sassalos, MD, ${ }^{\mathrm{c}}$ Jason R. Buckley, MD, ${ }^{\mathrm{d}}$ Arthur J. Smerling, MD, ${ }^{\mathrm{e}}$ Ilias Iliopoulos, $\mathrm{MD},{ }^{\mathrm{f}}$ Christine M. Riley, CPNP-AC, ${ }^{\mathrm{g}}$ Aimee Jennings, PNP-AC/PC, ${ }^{\mathrm{h}}$ Katherine Cashen, DO, ${ }^{\mathrm{i}}$ Sukumar Suguna Narasimhulu, MD, MPH, ${ }^{\mathrm{j}}$ Keshava Murty Narayana Gowda, MBBS, ${ }^{\mathrm{k}}$ Adnan M. Bakar, MD, ${ }^{1}$ Michael Wilhelm, MD, ${ }^{\mathrm{m}}$ Aditya Badheka, MD, ${ }^{\mathrm{n}}$ Elizabeth A. S. Moser, MS, ${ }^{\circ}$ and John M. Costello, MD, MPH, ${ }^{p}$ the Collaborative Research in Pediatric Cardiac Intensive Care Investigators

\section{ABSTRACT}

Objective: We sought to describe characteristics and operative outcomes of children who underwent repair of truncus arteriosus and identify risk factors for the occurrence of major adverse cardiac events (MACE) in the immediate postoperative period in a contemporary multicenter cohort.

Methods: We conducted a retrospective review of children who underwent repair of truncus arteriosus between 2009 and 2016 at 15 centers within the United States. Patients with associated interrupted or obstructed aortic arch were excluded. MACE was defined as the need for postoperative extracorporeal membrane oxygenation, cardiopulmonary resuscitation, or operative mortality. Risk factors for MACE were identified using multivariable logistic regression analysis and reported as odds ratios (ORs) with 95\% confidence intervals (CIs).

Results: We reviewed 216 patients. MACE occurred in 44 patients $(20 \%)$ and did not vary significantly over time. Twenty-two patients $(10 \%)$ received postoperative extracorporeal membrane oxygenation, $26(12 \%)$ received cardiopulmonary resuscitation, and $15(7 \%)$ suffered operative mortality. With multivariable logistic regression analysis (which included adjustment for center effect), factors independently associated with MACE were failure to diagnose truncus arteriosus before discharge from the nursery (OR, 3.1; 95\% CI, 1.3-7.4), cardiopulmonary bypass duration $>150$ minutes $(\mathrm{OR}, 3.5 ; 95 \% \mathrm{CI}, 1.5-8.5)$, and right ventricle-topulmonary artery conduit diameter $>50 \mathrm{~mm} / \mathrm{m}^{2}$ (OR, 4.7; 95\% CI, 2.0-11.1).

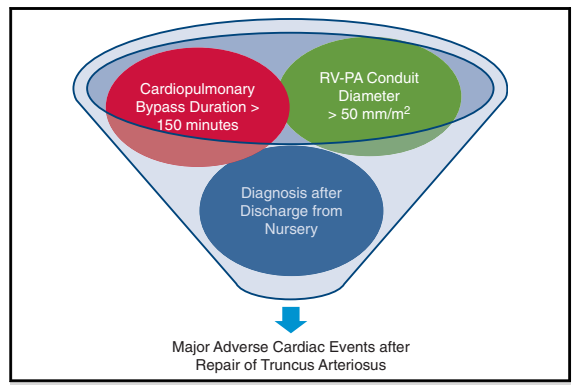

Modifiable risk factors for major adverse cardiac events after truncus arteriosus repair.

\section{Central Message}

One-fifth of children who underwent repair of truncus arteriosus suffered major adverse cardiac events. We identified potentially modifiable risk factors for the occurrence of these events.

\section{Perspective}

In a multicenter cohort, $20 \%$ of children suffered MACE after repair of truncus arteriosus. Diagnosis after nursery discharge, cardiopulmonary bypass duration $>150$ minutes, and right ventricleto-pulmonary artery conduit diameter $>50 \mathrm{~mm} / \mathrm{m}^{2}$ were identified as independent and potentially modifiable risk factors for MACE in these children.
From the a Division of Critical Care, Department of Pediatrics, Indiana University School of Medicine, Riley Hospital for Children, Indianapolis, Ind; ${ }^{b}$ Division of Critical Care Medicine, Department of Pediatrics, University of Utah School of Medicine, Primary Children's Hospital, Salt Lake City, Utah; ${ }^{\mathrm{c}}$ Section of Pediatric Cardiovascular Surgery, Department of Cardiac Surgery, University of Michigan, C.S. Mott Children's Hospital, Ann Arbor, Mich; ${ }^{\mathrm{d}}$ Division of Cardiology, Department of Pediatrics, Medical University of South Carolina Children's Hospital, Charleston, SC; ${ }^{\mathrm{e}}$ Division of Critical Care, Department of Pediatrics, Columbia University College of Physicians \& Surgeons, Morgan Stanley Children's Hospital of New York, New York, NY; ${ }^{\mathrm{f}}$ Division of Cardiac Critical Care, Department of Pediatrics, The Heart Institute, Cincinnati Children's Hospital Medical Center, Cincinnati, Ohio; ${ }^{\mathrm{g}}$ Division of Cardiac Critical Care, Department of Pediatrics,

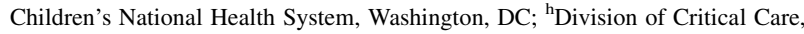
Department of Pediatrics, Seattle Children's Hospital, Seattle, Wash; ${ }^{\text {i Division }}$ of Critical Care, Department of Pediatrics, Wayne State University School of Medicine, Children's Hospital of Michigan, Detroit, Mich; ${ }^{j}$ Division of Cardiac Intensive Care, Department of Pediatrics, University of Central Florida College of Medicine, The Heart Center at Arnold Palmer Hospital for Children, Orlando, Fla; ${ }^{k}$ Division of Critical Care Medicine, Department of Pediatrics, Cleveland Clinic, Cleveland, Ohio; ' Division of Cardiac Critical Care, Department of Pediatrics, Zucker School of Medicine at Hofstra/Northwell, Cohen Children's Medical Center of NY, New Hyde Park, NY; ${ }^{\mathrm{m}}$ Division of Cardiac Intensive Care, Depart- ment of Pediatrics, University of Wisconsin, Madison, Wis; ${ }^{\mathrm{n}}$ Division of Critical Care Medicine, Department of Pediatrics, University of Iowa Stead Family Children's Hospital, Iowa City, Iowa; ${ }^{\circ}$ Department of Biostatistics, Indiana University School of Medicine and Richard M. Fairbanks School of Public Health, Indianapolis, Ind; and ${ }^{\mathrm{P}}$ Divisions of Cardiology and Critical Care Medicine, Department of Pediatrics, Ann and Robert H. Lurie Children's Hospital of Chicago, Northwestern University Feinberg School of Medicine, Chicago, Ill.

Funding from the Department of Pediatrics at Indiana University School of Medicine was provided for this study through a Riley Children's Foundation Grant (intramural) for administrative support.

Read at the 98th Annual Meeting of The American Association for Thoracic Surgery, San Diego, California, April 28-May 1, 2018.

Received for publication March 30, 2018; revisions received Nov 20, 2018; accepted for publication Dec 22, 2018; available ahead of print April 4, 2019.

Address for reprints: Christopher W. Mastropietro, MD, FCCM, Department of Pediatrics, Indiana University School of Medicine, Cardiac Intensive Care Unit, Riley Hospital for Children, 705 Riley Hospital Drive, Riley Phase 2, RI4119C, Indianapolis, IN 46202 (E-mail: cmastrop@iupui.edu).

$0022-5223 / \$ 36.00$

Copyright (C) 2019 by The American Association for Thoracic Surgery https://doi.org/10.1016/j.jtcvs.2018.12.115 


\section{Abbreviations and Acronyms \\ BSA = body surface area \\ CI $=$ confidence interval \\ $\mathrm{CPB} \quad=$ cardiopulmonary bypass \\ CPR = cardiopulmonary resuscitation \\ ECMO = extracorporeal membrane oxygenation \\ IAA = interrupted aortic arch \\ MACE = major adverse cardiac events \\ OR $\quad=$ odds ratio \\ RV-PA $=$ right ventricle-to-pulmonary artery \\ STS-CHSD $=$ Society of Thoracic Surgeons \\ Congenital Heart Surgery Database}

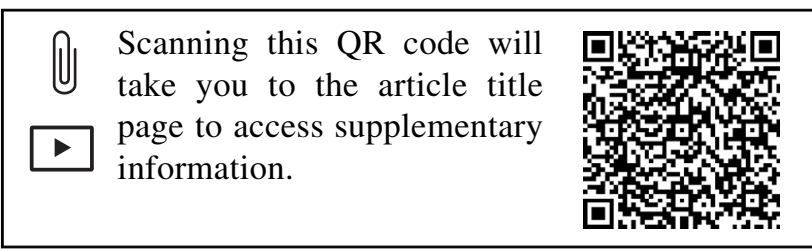

Conclusions: In a contemporary multicenter analysis, $20 \%$ of children who underwent repair of truncus arteriosus experienced MACE. Early diagnosis, shorter duration of cardiopulmonary bypass, and use of smaller diameter right ventricle-to-pulmonary artery conduits represent potentially modifiable factors that could decrease morbidity and mortality in this fragile patient population. (J Thorac Cardiovasc Surg 2019;157:2386-98)

Over the past 15 years, survival after surgery for congenital heart disease has steadily improved. ${ }^{1}$ For certain lesions, however, surgical mortality and the rate of postoperative complications remains relatively high. ${ }^{2-5}$ For children born with a common arterial trunk, or truncus arteriosus, surgical mortality between 2005 and 2009 reported from the Society of Thoracic Surgeons Congenital Heart Surgery Database (STS-CHSD) was $9.2 \%{ }^{2}$ More recently, operative mortality in neonates who underwent repair of truncus arteriosus between 2013 and 2016 was $10.8 \% .^{3}$ Another study from the STS-CHSD reported the need for extracorporeal membrane oxygenation (ECMO) after repair of truncus arteriosus to be $9.4 \%$, which was high relative to other operations, and mortality in this subset was $71 \%{ }^{4}$ The occurrence of other complications after repair of truncus arteriosus are also notably frequent relative to other lesions. ${ }^{5}$

Previous studies have identified moderate to severe truncal valve regurgitation or interrupted aortic arch (IAA) to be risk factors for mortality and complications after repair of truncus arteriosus. ${ }^{6-8}$ These coexistent lesions, however, represent a relatively small proportion of patients. Between 2000 and 2009, 572 patients were entered into the STS-CHSD as having surgical repair of truncus arteriosus, yet only 22 underwent concomitant repair of their truncal valve, 34 underwent concomitant repair of IAA, and 5 underwent concomitant repair of both additional lesions. ${ }^{6}$ Of the remaining 511 patients, $45(9 \%)$ died. Thus, a considerable portion of children with truncus arteriosus suffer early mortality despite the absence of IAA or concomitant truncal valve surgery.

To date, most data on operative outcomes after repair of truncus arteriosus are from single-center studies. ${ }^{7-15}$ These data, although useful, are often difficult to interpret and generalize because of variations in preoperative, surgical, and postoperative management that exist between centers. We aim to describe characteristics and operative outcomes of children who underwent repair of truncus arteriosus using a contemporary multicenter data set. From these data, we aim to identify risk factors for poor outcome after repair of truncus arteriosus, defined as the occurrence of major adverse cardiac events (MACE) in the postoperative period. We hypothesized that analysis of data compiled from multiple centers that includes variables not recorded in the STS-CHSD would allow us to identify previously unrecognized risk factors for poor outcome after repair of truncus arteriosus.

\section{METHODS}

\section{Study Population}

We performed a retrospective review of all patients who underwent primary surgical repair of truncus arteriosus at 15 tertiary care pediatric referral centers between 2009 and 2016. A list of participating institutions is provided in Table E1. The study was approved by the institutional review boards at all centers and was performed in accordance with the ethical standards laid down in the 1964 Declaration of Helsinki and its later amendments. Because of the retrospective nature of the data collected, the need for informed consent was waived.

The following patients were excluded from the analysis:

- Children who underwent pulmonary artery banding but died before repair

- Children with hemitruncus (ie, right pulmonary artery coming off the aorta) or pseudotruncus (ie, pulmonary atresia with major aortopulmonary collaterals)

- Children who underwent concomitant repair of truncus arteriosus with IAA or aortic arch obstruction (Van Praagh type A4), which is designated as a Society of Thoracic Surgeons-European Association for Cardio-Thoracic Surgery mortality category 5 procedure, in contrast to repair of truncus arteriosus (Van Praagh type A1-A3), which is a Society of Thoracic Surgeons-European Association for Cardio-Thoracic Surgery mortality category 4 procedure ${ }^{1}$ (data for children with this lesion will be reported by our research group elsewhere).

\section{Data Collection and Definitions}

A comprehensive list of variables and definitions is included in Table E2. Right ventricle-to-pulmonary artery (RV-PA) conduit diameter was 
TABLE 1. Comparison of patients with and without MACE after repair of truncus arteriosus (2009-2016); demographic information and baseline patient characteristics

\begin{tabular}{|c|c|c|c|c|}
\hline Variable* & All patients $(\mathrm{N}=\mathbf{2 1 6})$ & No MACE $(\mathbf{n}=172)$ & MACE $(n=44)$ & $P$ value \\
\hline Prenatal diagnosis & $135(63)$ & $111(65)$ & $24(55)$ & .22 \\
\hline Age at diagnosis, $\mathrm{d}$ & $0(0,2)$ & $0(0,1)$ & $0(0,3)$ & .13 \\
\hline Not diagnosed before discharge & $45(21)$ & $31(18)$ & $14(32)$ & .04 \\
\hline Sent home after diagnosis & $17(8)$ & $15(9)$ & $2(5)$ & .29 \\
\hline Not diagnosed before discharge or sent home after diagnosis & $62(29)$ & $46(27)$ & $16(36)$ & .21 \\
\hline Truncus type (Van Praagh) & & & & .15 \\
\hline A1 & $112(52)$ & $94(55)$ & $18(41)$ & \\
\hline A2 & $90(42)$ & $66(38)$ & $24(55)$ & \\
\hline A3 & $14(7)$ & $12(7)$ & $2(5)$ & \\
\hline Prematurity (<37 wk) & $42(19)$ & $30(17)$ & $12(27)$ & .14 \\
\hline Female sex & $108(50)$ & $87(51)$ & $21(48)$ & .74 \\
\hline Race & & & & .72 \\
\hline White & $147(68)$ & $119(69)$ & $28(64)$ & \\
\hline Black & $33(15)$ & $26(15)$ & $7(16)$ & \\
\hline Other/unknown & $36(17)$ & $27(16)$ & $9(20)$ & \\
\hline Latino/Hispanic ethnicity & $27(13)$ & $21(12)$ & $6(14)$ & .80 \\
\hline Any chromosomal anomaly & $83(38)$ & $68(40)$ & $15(34)$ & .51 \\
\hline DiGeorge/22q.11 deletion & $61(28)$ & $53(31)$ & $8(18)$ & .10 \\
\hline Noncardiac anatomic anomaly & $63(29)$ & $48(28)$ & $15(34)$ & .42 \\
\hline Year of surgical repair & & & & .24 \\
\hline 2009 & $17(8)$ & $14(8)$ & $3(7)$ & \\
\hline 2010 & $25(12)$ & $21(12)$ & $4(9)$ & \\
\hline 2011 & $31(14)$ & $21(12)$ & $10(23)$ & \\
\hline 2012 & $30(14)$ & $28(16)$ & $2(5)$ & \\
\hline 2013 & 27 (13) & $22(13)$ & $5(11)$ & \\
\hline 2014 & 28 (13) & $23(13)$ & $5(11)$ & \\
\hline 2015 & 34 (16) & 27 (16) & $7(16)$ & \\
\hline 2016 & $24(11)$ & $16(9)$ & $8(18)$ & \\
\hline
\end{tabular}

MACE, Major adverse cardiac events. *Continuous variables are represented as median (25th, 75th percentile); categorical data are represented as absolute counts $(\%)$.

indexed to body surface area (BSA) to adjust the absolute values for differences in body size across subjects. The primary outcome of interest was the occurrence of MACE defined as intraoperative or postoperative cardiopulmonary resuscitation (CPR), ECMO, or operative mortality. This composite outcome measure has been used elsewhere in the cardiac surgical literature. ${ }^{18,19}$

\section{Statistical Analysis}

Data are represented as medians with 25 th and 75th percentiles for continuous variables and absolute counts with percentages for categorical variables unless otherwise noted. To determine risk factors associated with MACE after repair of truncus arteriosus, we performed a bivariate analysis using Wilcoxon rank sum test, $\chi^{2}$ test, and Fisher exact test as appropriate for individual variables. All variables with $P$ values $<.2$ on bivariate analyses were considered for inclusion in our multivariate logistic regression model. The multivariable model was also analyzed as a mixed model with center as a random effect. We treated the effect of center on the model as a random (as opposed to fixed) variable because the centers involved in the study represent a random sample of the population of all congenital cardiac centers, with considerable variation in center volume, preoperative and postoperative care models, and geographic location. Linearity in the logit was examined for continuous variables before model-building; variables with evidence of nonlinearity were converted to categorical variables using receiver operative characteristic analysis to identify optimal cut points. This approach (as opposed to transformation of the continuous data) was chosen to facilitate clinical interpretation of the data analysis. Variables with $P$ values $<.05$ after multivariable analysis were identified as independent risk factors for MACE after surgical repair of truncus arteriosus. All statistical analyses were performed using STATA version 14 (StataCorp LP, College Station, Tex) and SAS version 9.4 (SAS Institute Inc, Cary, NC).

\section{RESULTS}

We retrospectively enrolled 216 children who underwent surgical repair of truncus arteriosus (Van Praagh type A1A3) between 2009 and 2016 at 15 institutions. Characteristics of the entire cohort are summarized in Tables 1 to 3 . Prenatal diagnosis occurred in $63 \%$ of patients, whereas $21 \%$ were not diagnosed before discharge from the nursery, with 14 patients $(6 \%)$ being diagnosed outside of the neonatal period ( $>30$ days). The distribution of age at diagnosis is depicted in Figure E1. The proportion of 
TABLE 2. Comparison of patients with and without MACE after repair of truncus arteriosus (2009-2016); preoperative clinical data

\begin{tabular}{|c|c|c|c|c|}
\hline Variable* & All patients $(N=216)$ & No MACE $(n=172)$ & $\operatorname{MACE}(n=44)$ & $P$ value \\
\hline \multicolumn{5}{|l|}{ Echocardiographic data } \\
\hline \multicolumn{5}{|l|}{ Ventricular function } \\
\hline Depressed RV function & $31(14)$ & $23(13)$ & $8(18)$ & .42 \\
\hline Depressed LV function & $22(10)$ & $15(9)$ & $7(16)$ & .17 \\
\hline Truncal valve anatomy & & & & .85 \\
\hline Bicuspid & $27(13)$ & $23(13)$ & $4(9)$ & \\
\hline Tricuspid & $114(53)$ & $89(52)$ & $25(57)$ & \\
\hline Quadricuspid & $73(34)$ & $58(34)$ & $15(34)$ & \\
\hline Dysplastic & $2(1)$ & $2(1)$ & $0(0)$ & \\
\hline Truncus valve insufficiency & & & & .38 \\
\hline Non/trivial & $99(46)$ & $83(48)$ & $16(36)$ & \\
\hline Mild & $51(24)$ & $41(24)$ & $10(23)$ & \\
\hline Mild to moderate/moderate & $49(23)$ & $36(21)$ & $13(30)$ & \\
\hline Moderate to severe/severe & $17(8)$ & $12(7)$ & $5(11)$ & \\
\hline Truncal valve stenosis & & & & .15 \\
\hline None & $153(71)$ & $121(70)$ & $32(73)$ & \\
\hline Mild/mild to moderate & $50(23)$ & $38(22)$ & $12(27)$ & \\
\hline Moderate/severe & $13(6)$ & $13(8)$ & $0(0)$ & \\
\hline Coronary artery abnormalities & $28(13)$ & $21(12)$ & $7(16)$ & .52 \\
\hline Preoperative shock & $21(10)$ & $12(7)$ & $9(20)$ & .02 \\
\hline Preoperative inotropic infusion $\dagger$ & $35(16)$ & $27(16)$ & $8(18)$ & .69 \\
\hline Preoperative ventilation $\ddagger$ & $45(21)$ & $34(20)$ & $11(25)$ & .45 \\
\hline Preoperative infection & $27(13)$ & $25(15)$ & $2(5)$ & .07 \\
\hline Preoperative seizures & $6(3)$ & $6(4)$ & $0(0)$ & .35 \\
\hline Preoperative stroke & $7(3)$ & $7(4)$ & $0(0)$ & .17 \\
\hline Pulmonary artery banding & $3(1)$ & $3(2)$ & $0(0)$ & 1.00 \\
\hline
\end{tabular}

$M A C E$, Major adverse cardiac events; $R V$, right ventricular; $L V$, left ventricular. *Continuous variables are represented as median (25th, 75 th percentile); categorical data are represented as absolute counts (\%). †Dopamine, dobutamine, epinephrine, and milrinone infusion(s) within 24 hours of surgery. $\ddagger$ Includes only patients who required endotracheal intubation at any point preoperatively and continued mechanical ventilation until surgery.

patients diagnosed prenatally and after discharge from the nursery did not vary significantly over time (Figure E2) and did not vary significantly across centers $(P=.13$ for both relationships). However, 17 patients $(8 \%)$ in the study were discharged to home after their diagnosis was confirmed, with a plan of medical management and elective surgery at a later date. Twelve of these patients $(71 \%)$ were readmitted before their scheduled surgery for acute respiratory failure or congestive heart failure. Moreover, 3 of the children developed necrotizing enterocolitis ( 1 of whom underwent surgical intervention for perforation) and 2 suffered cardiac arrests ( 1 of whom received preoperative ECMO support) before their surgical repair.

Operatively, 191 patients $(88 \%)$ received 1 of 3 types of RV-PA conduits: pulmonary allograft, aortic allograft, or Contegra (Medtronic Inc, Minneapolis, Minn) bovine jugular vein conduit. Of the remaining 25 patients, 13 patients received femoral vein allografts, 2 patients received GORETEX (W.L. Gore \& Associates Inc, Flagstaff, Ariz) conduits, 1 patient received a conduit created from anterior pericardium, 8 patients underwent direct anastomosis of their main pulmonary artery segment to their right ventricle (with or without patch augmentation), and 1 patient with a coexisting unbalanced atrioventricular septal defect had a systemic-to-pulmonary artery shunt placed. For the 209 patients who received RV-PA conduits, the range of the absolute values for the RV-PA conduit diameters used was relatively narrow, with all but 3 of these patients receiving a conduit with a diameter between $8 \mathrm{~mm}$ and $14 \mathrm{~mm}$. When indexed to BSA, this range of RV-PA conduit diameters was $29 \mathrm{~mm} / \mathrm{m}^{2}$ to $78 \mathrm{~mm} / \mathrm{m}^{2}$.

For the entire patient population, median postoperative duration of mechanical ventilation was 5 days (range, 1148 ), median hospital length of stay was 23 days (range, 6-282), and operative mortality was $6.9 \%(n=15)$. MACE occurred in 44 patients $(20 \%)$. The proportions who suffered each type of MACE or other complications are provided in Table E3, and variation in MACE and operative mortality across institutions is provided in Figure 1. Of note, operative mortality in the 22 patients who received ECMO was $36 \%(n=8)$. Bivariate analysis of demographic data, underlying comorbidities, and preoperative 
TABLE 3. Comparison of patients with and without MACE after repair of truncus arteriosus (2009-2016); operative data

\begin{tabular}{|c|c|c|c|c|}
\hline Variable* & All patients $(N=216)$ & No MACE $(n=172)$ & $\operatorname{MACE}(n=44)$ & $P$ value \\
\hline Age at surgery, $d$ & $10(7,24)$ & $9.5(7,23)$ & $11(6.5,32)$ & .38 \\
\hline $\begin{array}{l}\text { Time from diagnosis to } \\
\text { surgery, } \mathrm{d}\end{array}$ & $8(5.5,15)$ & $7.5(5.5,15)$ & $9(5.5,18)$ & .46 \\
\hline Weight at surgery (kg) & $3.1(2.7,3.5)$ & $3.1(2.7,3.5)$ & $3(2.5,3.5)$ & .39 \\
\hline Body surface area, $\mathrm{m}^{2}$ & $0.21(0.19,0.23)$ & $0.21(0.19,0.23)$ & $0.21(0.18,0.23)$ & .60 \\
\hline Cardiopulmonary bypass, min & $150(124,186)$ & $144(122,182)$ & $165(141,235)$ & $<.01$ \\
\hline $\begin{array}{l}\text { Cardiopulmonary bypass } \\
>150 \mathrm{~min}\end{array}$ & $107(50)$ & $78(45)$ & $29(66)$ & .02 \\
\hline Aortic cross clamp time, min & $86(73,111)$ & $87(70,110)$ & $85(78,116)$ & .34 \\
\hline $\begin{array}{l}\text { Hypothermic circulatory } \\
\text { arrest }\end{array}$ & $31(14)$ & $24(14)$ & $7(16)$ & .74 \\
\hline Lowest temperature, ${ }^{\circ} \mathrm{C}$ & $25(21,28)$ & $25(22,28)$ & $25(21,28)$ & .95 \\
\hline Modified ultrafiltration & $139(64)$ & $113(66)$ & $26(59)$ & .41 \\
\hline Intraoperative steroids & $161(75)$ & $132(77)$ & $29(67)$ & .14 \\
\hline Intraoperative factor VIIa & $34(16)$ & $26(15)$ & $8(18)$ & .62 \\
\hline $\begin{array}{l}\text { RV-PA conduit type } \\
\text { Aortic allograft } \\
\text { Pulmonary allograft } \\
\text { Contegra conduit } \\
\text { Other/none }\end{array}$ & $\begin{array}{l}53(25) \\
83(38) \\
55(26) \\
25(12)\end{array}$ & $\begin{array}{l}42(24) \\
72(42) \\
37(22) \\
21(12)\end{array}$ & $\begin{array}{c}11(25) \\
11(25) \\
18(41) \\
4(9)\end{array}$ & .04 \\
\hline RV-PA conduit size, $\mathrm{mm}^{\dagger}$ & $11(9,12)$ & $10(9,12)$ & $12(9,12)$ & .22 \\
\hline RV-PA conduit size, $\mathrm{mm} / \mathrm{m}^{2} \dagger$ & $51(45.6,56.4)$ & $49.9(44.9,55.5)$ & $52.9(49,57.3)$ & .01 \\
\hline $\begin{array}{l}\text { RV-PA conduit size }>50 \mathrm{~mm} / \\
\mathrm{m}^{2}\end{array}$ & $112(52)$ & $79(46)$ & $33(75)$ & $<.01$ \\
\hline Truncal valve repaired & $34(16)$ & $25(15)$ & $9(21)$ & .34 \\
\hline Truncal valve replaced & $6(3)$ & $3(2)$ & $3(7)$ & .10 \\
\hline Pulmonary artery banding & $3(1)$ & $3(2)$ & $0(0)$ & 1.00 \\
\hline
\end{tabular}

Contegra conduits are from Medtronic Inc (Minneapolis, Minn). MACE, Major adverse cardiac events; $R V-P A$, right ventricle-to-pulmonary artery. *Continuous variables are represented as median (25th, 75th percentile); categorical data are represented as absolute counts (\%). $\uparrow \mathrm{n}=207$ patients; excludes 8 patients who underwent direct anastomoses of main pulmonary artery segment and 1 patient who underwent placement of systemic-to-pulmonary artery shunt.

and operative variables is included in Tables 1 to 3 . Preoperatively, patients who experienced MACE were significantly more likely to have been diagnosed after discharge from the nursery and more likely to have developed shock, although patients who were diagnosed after discharge from the nursery were not more likely to develop shock preoperatively_4 of 45 children $(9 \%)$ compared with 17 of 171 children $(10 \%)$ diagnosed prenatally or before nursery discharge $(P=1.00)$.

We also found that patients with MACE had longer duration of cardiopulmonary bypass (CPB) and larger diameter RV-PA conduits (indexed to BSA), whereas aortic crossclamping duration, use of deep hypothermic circulatory arrest, and lowest targeted temperature during surgery were not statistically different between patients with and without MACE. Using receiver operative characteristic analysis, we identified CPB duration greater than 150 minutes and RV-
PA conduit diameter greater than $50 \mathrm{~mm} / \mathrm{m}^{2}$ as optimal cut-points for prediction of MACE. The relationships between MACE, RV-PA conduit diameter, and BSA are illustrated in Figure 2, where the significant increase in the MACE in patients with RV-PA conduit diameter greater than $50 \mathrm{~mm} / \mathrm{m}^{2}$ can be visually appreciated. In contrast, the occurrence of MACE was relatively evenly distributed across different body sizes. Moreover, we noted a significantly higher proportion of MACE in patients who received Contegra conduits, although conduit diameter was significantly larger in the 55 patients who received Contegra conduits, median $54 \mathrm{~mm} / \mathrm{m}^{2}$ (range, 48-57), compared with the 136 patients who received pulmonary or aortic allografts, median $50 \mathrm{~mm} / \mathrm{m}^{2}$ (range, 44-54; $P<.01$ ).

The results of our mixed effects logistic regression analysis are provided in Table 4, including odds ratios (ORs) and $95 \%$ confidence intervals (CIs) for the fixed effects 


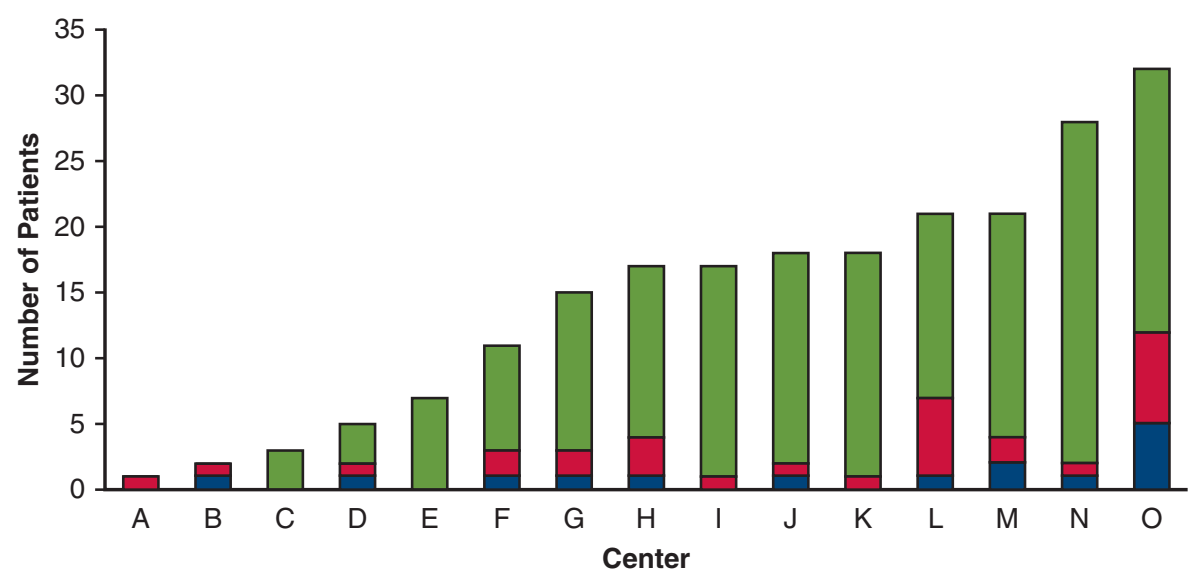

FIGURE 1. Variation across centers in the number of patients who underwent repair of truncus arteriosus and the occurrence of major adverse cardiovascular events. Each bar contains the number of patients who suffered operative mortality (blue portion), number who suffered cardiac arrest or received extracorporeal membrane oxygenation but survived (red portion), and number who did not suffer major adverse cardiovascular events (green portion of bars). Centers are arranged in order of increasing surgical volume of patients who underwent truncus arteriosus repair during the study period.

adjusted for center. We identified diagnosis after discharge from the nursery, CPB duration $>150$ minutes, and RV-PA conduit diameter $>50 \mathrm{~mm} / \mathrm{m}^{2}$ as factors independently associated with MACE after repair of truncus arteriosus in a model that included preoperative shock. The relationship between the CPB duration and RV-PA conduit diameter with postoperative complications is further explored in
Figure 3. Operative mortality, CPR, delayed sternal closure, and postoperative tachyarrhythmias were significantly more common in patients with larger diameter RV-PA conduits (Figure $3, A$ ). In contrast, operative mortality, ECMO, and inhaled nitric oxide use were significantly more frequent in patients with prolonged $\mathrm{CPB}$ duration (Figure 3, B).

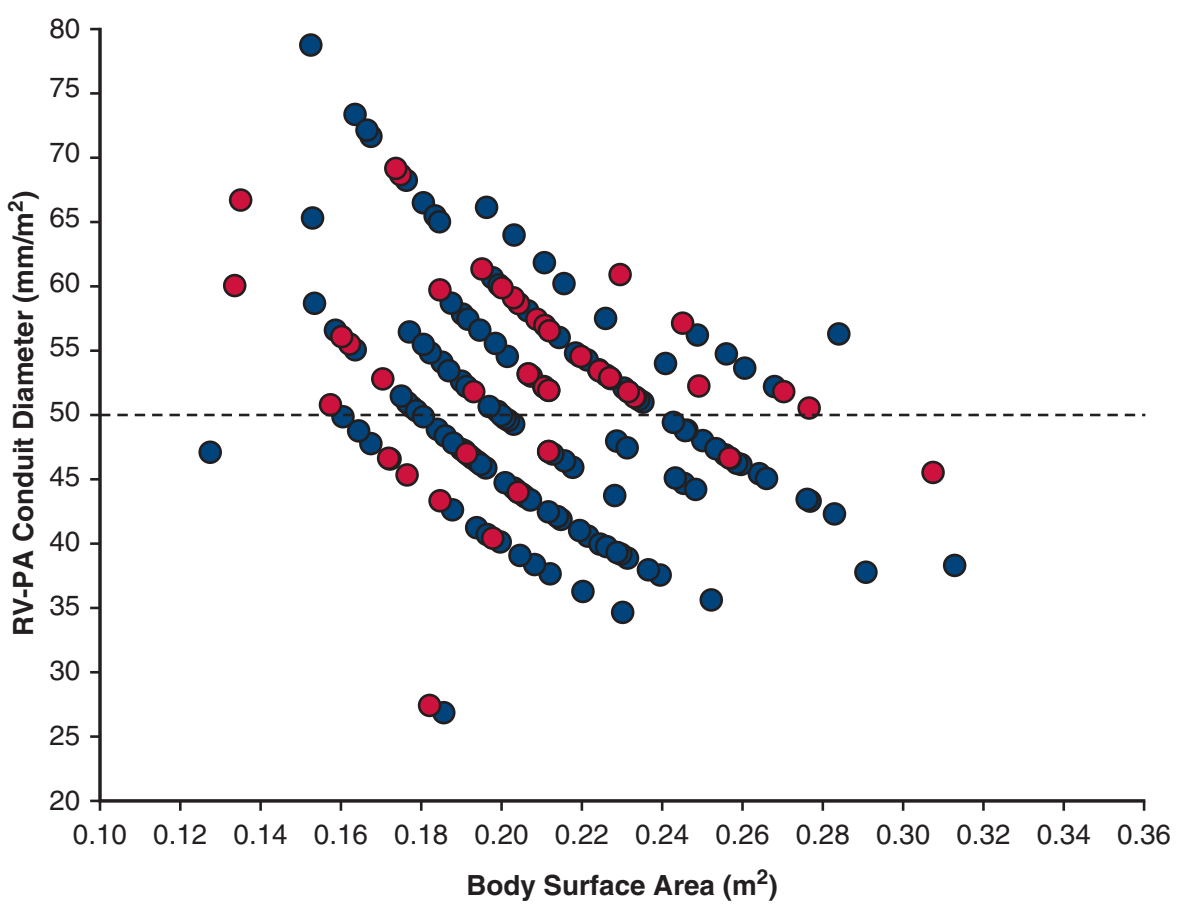

FIGURE 2. Major adverse cardiovascular events (MACE) in relation to body surface area and the diameter of surgically-placed right ventricle-topulmonary artery $(R V-P A)$ conduit in patients who underwent repair of truncus arteriosus. Patients who experienced MACE $(\mathrm{n}=44$, red circles) were significantly more likely to have RV-PA conduits $>50 \mathrm{~mm} / \mathrm{m}^{2}$ in diameter (dotted reference line) than patients who did not experience MACE. Specifically, 33 of 44 patients $(75 \%)$ who suffered MACE had RV-PA conduits $>50 \mathrm{~mm} / \mathrm{m}^{2}$, compared with 79 of 172 patients $(46 \%)$ who did suffer MACE $(P<.01)$. Importantly, though smaller patients were more likely to have larger diameter RV-PA conduits, no significant relationship between the occurrence of MACE and body size was observed. 
TABLE 4. Multivariable logistic regression analysis for predictors of operative mortality after repair of truncus arteriosus (analyzed as a mixed model with a random effect of center)

\begin{tabular}{lcc}
\hline \multicolumn{1}{c}{ Fixed effects } & $\begin{array}{c}\text { Odds ratio }(\mathbf{9 5} \% \\
\text { confidence interval) }\end{array}$ & $\boldsymbol{P}$ value \\
\hline Preoperative shock & $3.0(0.97-9.5)$ & .06 \\
$\begin{array}{l}\text { Undiagnosed at discharge from } \\
\text { nursery }\end{array}$ & $3.1(1.3-7.4)$ & .01 \\
Cardiopulmonary bypass $>150 \mathrm{~min}$ & $3.5(1.5-8.5)$ & $<.01$ \\
RV-PA conduit size $>50 \mathrm{~mm} / \mathrm{m}^{2}$ & $4.7(2.0-11.1)$ & $<.01$ \\
\hline
\end{tabular}

$R V$ - $P A$, Right ventricle-to-pulmonary artery.

We notably did not find an increased occurrence rate of MACE patients who underwent concomitant surgical intervention on their truncal valve (Table 2). It should be noted that of the 6 patients who underwent truncal valve replacement at the time of the surgery, MACE occurred in the 3 patients who first underwent an attempt at truncal valve repair and then underwent a second course of CPB and truncal valve replacement during the same operation (CPB durations: 333, 336, and 356 minutes), whereas no MACE occurred in the 3 patients who underwent truncal valve replacement without a previous attempt at truncal valve repair (CPB durations: 217, 291, and 323 minutes). Accordingly, to better examine whether the association of MACE and prolonged $\mathrm{CPB}$ duration was more related to the duration of $\mathrm{CPB}$ itself or the need for concomitant truncal valve intervention that contributed to the prolonged duration of $\mathrm{CPB}$, we performed a sensitivity analysis excluding the 37 patients who underwent truncal valve interventions. In this mixed effects logistic regression analysis, which included adjustments for preoperative shock as a fixed effect and center as a random effect, failure to diagnose truncus arteriosus before nursery discharge (OR, $2.8 ; 95 \% \mathrm{CI}$, 1.1-7.4), CPB duration $>150$ minutes (OR, 3.0; $95 \% \mathrm{CI}$, 1.1-7.7), and RV-PA conduit diameter $>50 \mathrm{~mm} / \mathrm{m}^{2}$ (OR, $3.3 ; 95 \%$ CI, 1.3-8.2) remained independently associated with MACE. A summary of these results can also be viewed in Video 1.

\section{DISCUSSION}

In this contemporary multicenter data set, we found that 1 in 5 patients who underwent surgical repair of truncus arteriosus suffered MACE. Furthermore, although operative mortality was lower than in previous reports from the STS-CHSD, especially in patients requiring ECMO, ${ }^{2,4}$ the occurrence of MACE did not decrease appreciably during the study period and complications were frequent relative to other neonatal operations. For example, $58 \%$ of patients in our study underwent delayed sternal closure (planned or unplanned), in contrast to $21 \%$ of all neonates reported to the STS-CHSD between 2013 and
$2016 .{ }^{3}$ Similarly, $6 \%$ of children in our study required tracheostomy, compared with $<1 \%$ of all patients reported to the STS-CHSD between 2010 and $2015 .{ }^{20}$ In other words, although operative mortality for patients who undergo surgery for congenital heart disease might be improving, patients with truncus arteriosus remain at considerable risk for complications and adverse cardiac events including death after surgery.

Fortunately, we identified 3 independent and potentially modifiable risk factors for MACE after repair of truncus arteriosus: failure to diagnose truncus arteriosus before discharge from the nursery, CPB duration $>150$ minutes, and RV-PA conduit diameter $>50 \mathrm{~mm} / \mathrm{m}^{2}$. Interestingly, in our multivariable analysis, diagnosis after discharge from the nursery (ie, late diagnosis) was associated with MACE independent of preoperative shock. On the basis of this analysis, we speculate that many patients who were diagnosed late presented in an advanced state of compensated congestive heart failure that had not yet progressed to meet the STS-CHSD definition of shock, and neonates need not progress to a late stage of shock before their burden of illness will influence their postoperative course. Early diagnosis before the development of shock with lactic acidosis should therefore be the aim of current neonatal screening protocols.

In 2009, the American Academy of Pediatrics and American Heart Association published a joint statement on pulse oximetry screening as a means to detecting undiagnosed congenital heart disease before nursery discharge. ${ }^{21}$ In 2012, the Department of Health and Human Services endorsed this practice. ${ }^{22}$ In 2017, data from the National Center for Health Statistics showed a significant decrease in infant cardiac deaths between 2007 and 2013 in states that had implemented statewide mandatory policies for newborn screening for critical congenital heart disease compared with states without these policies. ${ }^{23}$ As of 2017, all states except Idaho and Kansas mandate newborn screening for critical congenital heart disease. ${ }^{24}$ Data on the adherence to these practices at individual centers, however, are sparse. In one recent report from a center where the practice of routine pulse oximetry screening for congenital heart disease was adopted and then audited, compliance with their protocol was $88 \%$, which is good but not optimal. ${ }^{25}$ The association of late diagnosis with MACE after repair of truncus arteriosus in our study and the aforementioned data on the benefits of routine pulse oximetry screening for congenital heart disease support the further expansion of this practice and the establishment of infrastructure at the local level to ensure that these programs are operating appropriately.

It should also be noted that 17 patients were discharged to home after diagnosis, of whom $71 \%$ were readmitted with life-threatening illnesses before repair. This observation 

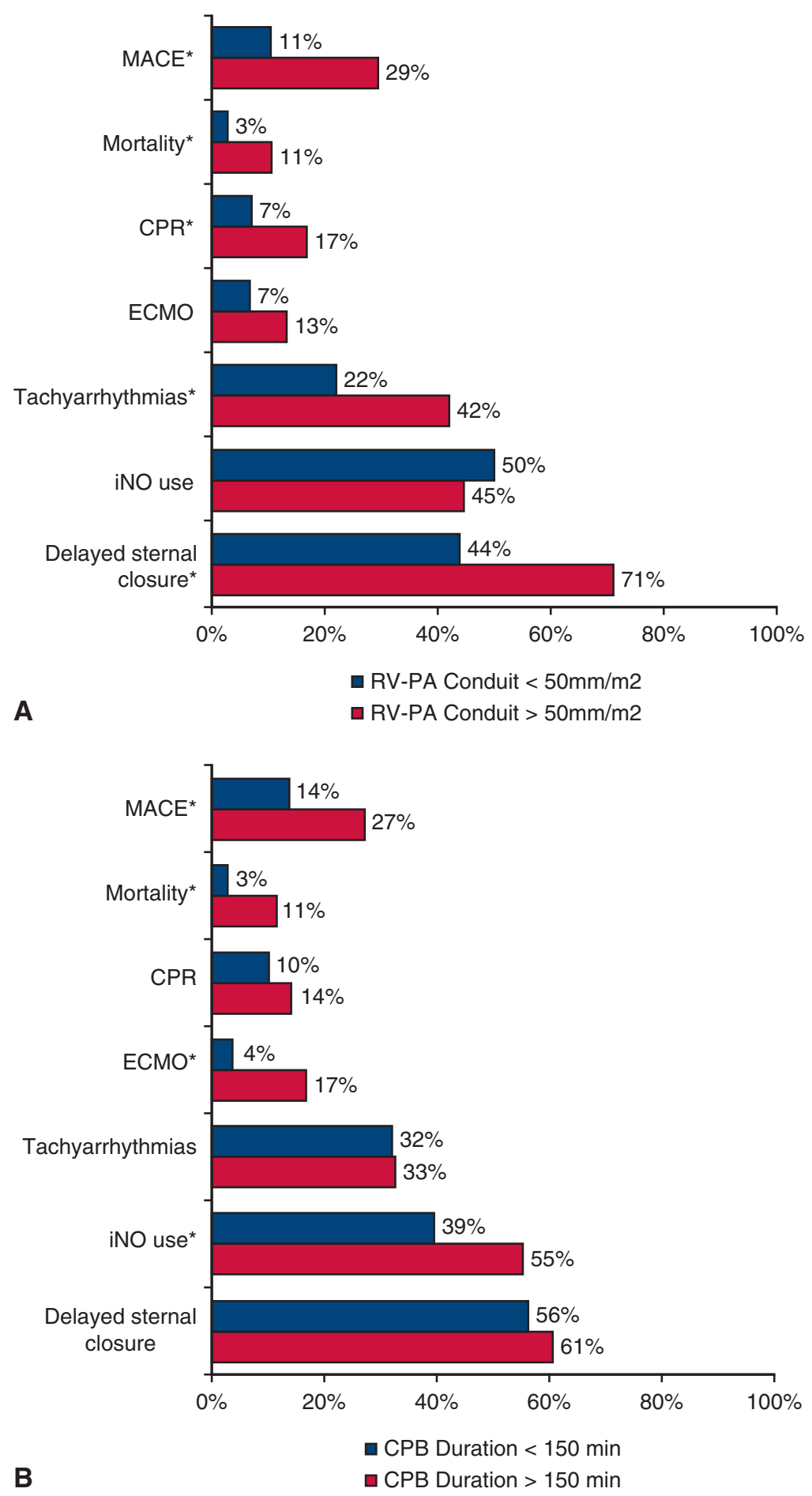

FIGURE 3. A, Patients with right ventricle-to-pulmonary artery $(R V-P A)$ conduits $>50 \mathrm{~mm} / \mathrm{m}^{2}$ in diameter were significantly more likely to suffer operative mortality and receive cardiopulmonary resuscitation $([C P R]$ ie, major cardiac adverse events $[M A C E])$. Patients with RV-PA conduits $>50 \mathrm{~mm} / \mathrm{m}^{2}$ were also more likely to experience tachyarrhythmias or undergo delayed sternal closure. In contrast, use of extracorporeal membrane oxygenation $(E C M O)$ or inhaled nitric oxide $(i N O)$ were not significantly more likely to occur in patients with conduit diameters $>50 \mathrm{~mm} / \mathrm{m}^{2}$. B, Patients with cardiopulmonary bypass $(C P B)$ duration $>150$ minutes were more likely to suffer operative mortality and receive ECMO (ie, MACE), and more likely to be administered iNO. The occurrence of CPR, tachyarrhythmias, and delayed sternal closure, however, were not statistically more likely in patients with CPB durations $>150$ minutes. *Statistically significant, $P<.05$. 


\section{Background}

- Truncus arteriosus

- Complex defect most commonly diagnosed in the neonatal period or early infancy

- Operative morbidity and mortality continues to be significant

- Risk factors for poor outcomes following surgical repair have been reported in single-center studies

\section{四}

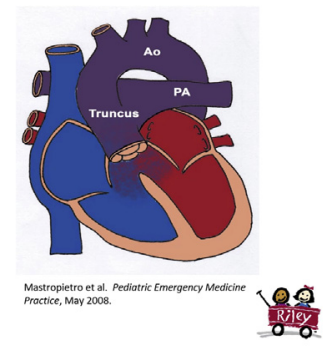

VIDEO 1. A PowerPoint slideshow accompanied by audio explanations for each slide featuring the most notable findings of our study. Video available at: https://www.jtcvs.org/article/S0022-5223(19)30530-6/fulltext.

argues against sending these children home without surgical intervention. Indeed, the feasibility and practicality of performing the surgical repair of truncus arteriosus in the neonatal period have long been established and confirmed by many single center studies. ${ }^{7,9-11}$ Thus, early surgical intervention for repair of truncus arteriosus should be pursued whenever possible to minimize the risk of preoperative morbidity.

Prolonged duration of CPB is a well-described risk factor for worse outcomes after pediatric cardiac surgery. ${ }^{26,27}$ On the basis of the observed association between longer duration of CPB and use of ECMO or inhaled nitric oxide, we presume that longer durations of $\mathrm{CPB}$ in our patients could have predisposed them to myocardial depression and pulmonary hypertensive crises that necessitated these adjunctive therapies. Notably, the relationship between prolonged CPB duration and adverse outcomes persisted when operations with concomitant truncal valve procedures were excluded. We are not, however, advocating that the quality of repair be sacrificed in an effort to be more expeditious. Rather, awareness of the association between MACE and prolonged duration of CPB after repair of truncus arteriosus should emphasize the importance of minimizing exposure to CPB whenever possible.

Perhaps the most compelling and easily modifiable identified risk factor for MACE after repair of truncus arteriosus is larger diameter of the RV-PA conduit, specifically $>50 \mathrm{~mm} / \mathrm{m}^{2}$. (For reference, in Figure E3, absolute RVPA conduit diameters that fall below the threshold of $50 \mathrm{~mm} / \mathrm{m}^{2}$ for BSAs between $0.15 \mathrm{~m}^{2}$ and $0.25 \mathrm{~m}^{2}$ are provided.) In a single-center study of 83 patients, Tlaskal and colleagues also noted a trend toward increased mortality in patients with larger absolute RV-PA conduit diameters. ${ }^{12}$ To our knowledge, our study represents the first to examine RV-PA conduit diameter indexed to BSA as an important variable to consider when planning surgical correction for these children. On the basis of our data, the pathophysiologic explanation for this finding cannot be clearly discerned. We speculate that larger diameter conduits could be associated with increased ventriculotomy size relative to the size of the neonatal myocardium, which could exacerbate restrictive right ventricular physiology or provide an arrhythmogenic substrate during the recovery period. Larger conduits could suffer from distortion or compression during sternal closure leading to conduit insufficiency, pulmonary artery distortion, or prolonged duration of open sternotomy, predisposing patients to infectious or respiratory complications. A combination of these possibilities could be responsible for the worse outcomes in patients with conduit diameters $>50 \mathrm{~mm} / \mathrm{m}^{2}$. Future studies on the relationship between conduit size and postoperative outcomes should be designed to more specifically investigate these or other potential pathophysiologic mechanisms.

Nearly all patients who undergo repair of truncus arteriosus will require replacement of their RV-PA conduit later in life and, consequently, many surgeons will err on the side of larger conduit diameters in an attempt to extend the period of time before conduit revision is needed. Indeed, several studies have associated smaller absolute conduit diameter with earlier need for reintervention, ${ }^{28-}$ 31 with some authors advocating "oversizing" of the conduit to prevent early graft failure. ${ }^{30}$ In a seminal study from the Congenital Heart Surgery Society of 429 children with various congenital heart lesions who required RV-PA conduits, use of smaller conduits were associated with earlier reinterventions, leading the authors to conclude "insertion of the largest conduit possible (within the constraints of our data and patient size) would be expected to postpone explantation prompted by the somatic growth of the patient." 31 On the basis of our data, use of larger conduits to promote long-term durability could come at a cost for some patients. None of the 8 patients who underwent direct anastomoses of the pulmonary artery suffered MACE, and studies have reported longer freedom from reoperation in patients who underwent direct anastomoses. $^{32-34}$ Additionally, a recent study reported that modified repair of truncus arteriosus in which the branch pulmonary arteries are left in situ and septated from the truncal root might promote conduit longevity. ${ }^{35}$ Further research focused on these modifications or other innovations could mitigate the impetus to use larger conduits at the initial repair of truncus arteriosus and, possibly, reduce the risk of MACE. Accordingly, additional research in children with congenital heart disease who receive RV-PA conduits should aim to determine a range of conduit diameters that could optimally balance the risks of shortand long-term morbidity and mortality.

This study has the limitations inherent to its retrospective design. For example, data on RV-PA conduit diameter were obtained retrospectively from operative reports and not confirmed by direct measurement via postoperative echocardiogram. If actual RV-PA conduit diameters 
differed from what was provided by the tissue record, the accuracy of our RV-PA conduit measurements would be affected. We also acknowledge that the components of our composite primary outcome measure differ in terms of severity (ie, mortality is a worse outcome than CPR or ECMO alone). However, etiologies for the need for CPR, need for ECMO, or operative mortality were likely similar in many patients (eg, myocardial depression, pulmonary hypertensive crises, arrhythmias, multiorgan dysfunction) and most clinicians would agree that any of the 3 included outcomes are undesirable. Notably, we did not include long-term outcomes in this study but rather maintained the focus on early outcomes. Last, patients for this study were identified in institutional surgical databases, which did not allow us to report data on patients who might have been diagnosed with truncus arteriosus but died before surgical intervention. The strength of this study is its collaborative multicenter design, which allowed us to obtain data on variables not entered into current databases such as the STS-CHSD as well as identify risk factors for MACE after repair of truncus arteriosus that are independent of center. Future analyses will focus on postdischarge outcomes including freedom from conduit intervention, truncal valve intervention, or death.

\section{CONCLUSIONS}

Operative mortality and other adverse cardiac events after repair of truncus arteriosus continue to be relatively common. In our contemporary multicenter study, operative mortality was $6.9 \%$ and MACE occurred in one-fifth of patients. We hope that future investigations will reveal that attention to the independent and potentially modifiable risk factors identified in this report-diagnosis after discharge from the nursery, duration of $\mathrm{CPB}>150$ minutes, and RV-PA conduit diameter $>50 \mathrm{~mm} / \mathrm{m}^{2}$ - will lead to improvements in the operative and early postoperative outcomes in these fragile children. We also suggest that neonatal repair becomes the preferred option for surgical timing at all centers, because patients who are discharged to home with medical management after diagnosis of truncus arteriosus are at considerable risk of preoperative morbidity.

\section{Webcast}

You can watch a Webcast of this AATS meeting presentation by going to: https://aats.blob.core.windows.net/ media/18Apr29/30ABC\%20Congenital\%20SS/S52_6_ webcast_044305416.mp4.

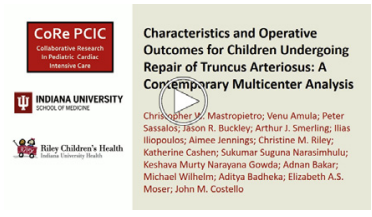

\section{Conflict of Interest Statement}

Authors have nothing to disclose with regard to commercial support

The authors acknowledge and thank the following individuals who assisted with administrative tasks, data collection, or review of echocardiograms for this study:

- Amy Moravec, BS, Ann \& Robert H. Lurie Children's Hospital of Chicago

- Kari Nelson, BA, MSN, CPNP, University of WisconsinAmerican Family Children's Hospital

- Josh Belfer, MD, Resident in Pediatrics, Cohen Children's Medical Center of New York

- Eva Cheung, MD, Assistant Professor, Department of Pediatrics, Division of Cardiology, Columbia University College of Physicians \& Surgeons, Morgan Stanley Children's Hospital of New York, New York, New York

- Linda M. Lambert, MSN-cFNP, Administrative Director of Research, Heart Center-Primary Children's Hospital, University of Utah

- Lisa Michelle Hansen, Clinical Research Coordinator, Heart Center-Primary Children's Hospital, University of Utah

\section{References}

1. Jacobs JP, He X, Mayer JE Jr, Austin EH III, Quintessenza JA, Karl TR, et al. Mortality trends in pediatric and congenital heart surgery: an analysis of the Society of Thoracic Surgeons Congenital Heart Surgery Database. Ann Thorac Surg. 2016;102:1345-52.

2. Jacobs JP, O'Brien SM, Pasquali SK, Jacobs ML, Lacour-Gayet FG, Tchervenkov CI, et al. Variation in outcomes for benchmark operations: an analysis of the Society of Thoracic Surgeons Congenital Heart Surgery Database. Ann Thorac Surg. 2011;92:2184-91.

3. Society of Thoracic Surgeons. STS Congenital Heart Surgery Data Summary; Neonates. Available at: https://www.sts.org/sites/default/files/documents/ CHSD_ExecutiveSummary_Neonates_Spring2017.pdf. Accessed March 2018.

4. Mascio CE, Austin EH III, Jacobs JP, Jacobs ML, Wallace AS, He X, et al. Perioperative mechanical circulatory support in children: an analysis of the Society of Thoracic Surgeons Congenital Heart Surgery Database. J Thorac Cardiovasc Surg. 2014;147:658-64.

5. Mavroudis C, Jacobs JP, Siegel A, Pasquali SK, Hill KD, Jacobs ML. Procedurebased complications to guide informed consent: analysis of Society of Thoracic Surgeons-Congenital Heart Surgery Database. Ann Thorac Surg. 2014;97:1838-49.

6. Russell HM, Pasquali SK, Jacobs JP, Jacobs ML, O'Brien SM, Mavroudis C, et al. Outcomes of repair of common arterial trunk with truncal valve surgery: a review of the Society of Thoracic Surgeons Congenital Heart Surgery Database. Ann Thorac Surg. 2012;93:164-9.

7. Thompson LD, McElhinney DB, Reddy VM, Petrossian E, Silverman NH, Hanley FL. Neonatal repair of truncus arteriosus: continuing improvement in outcomes. Ann Thorac Surg. 2001;72:391-5.

8. Brown JW, Ruzmetov M, Okada Y, Vijay P, Turrentine MW. Truncus arteriosus repair: outcomes, risk factors, reoperation and management. Eur J Cardiothorac Surg. 2001;20:221-7

9. Hanley FL, Heinemann MK, Jonas RA, Mayer JE Jr, Cook NR, Wessel DL, et al. Repair of truncus arteriosus in the neonate. J Thorac Cardiovasc Surg. 1993;105: 1047-56.

10. Bove EL, Lupinetti FM, Pridjian AK, Beekman RH III, Callow LB, Snider AR, et al. Results of a policy of primary repair of truncus arteriosus in the neonate. $J$ Thorac Cardiovasc Surg. 1993;105:1057-65.

11. Kalavrouziotis G, Purohit M, Ciotti G, Corno AF, Pozzi M. Truncus arteriosus communis: early and midterm results of early primary repair. Ann Thorac Surg. 2006;82:2200-6.

12. Tlaskal T, Chaloupecky V, Hucin B, Gebauer R, Krupickova S, Reich O, et al. Long-term results after correction of persistent truncus arteriosus in 83 patients. Eur J Cardiothorac Surg. 2010;37:1278-84. 
13. Sandrio S, Rüffer A, Purbojo A, Glöckler M, Dittrich S, Cesnjevar R. Common arterial trunk: current implementation of the primary and staged repair strategies. Interact Cardiovasc Thorac Surg. 2015;21:754-60.

14. Martin BJ, Ross DB, Alton GY, Joffe AR, Robertson CM, Rebeyka IM, et al. Clinical and functional developmental outcomes in neonates undergoing truncus arteriosus repair: a cohort study. Ann Thorac Surg. 2016;101:1827-33.

15. Chen Q, Gao H, Hua Z, Yang K, Yan J, Zhang H, et al. Outcomes of surgical repair for persistent truncus arteriosus from neonates to adults: a single center's experience. PLoS One. 2016;11:e0146800.

16. Calder L, Van Praagh R, Van Praagh S, Sears WP, Corwin R, Levy A, et al. Truncus arteriosus communis. Clinical, angiocardiographic, and pathologic findings in 100 patients. Am Heart J. 1976;92:23-38.

17. Society of Thoracic Surgeons. STS Congenital Heart Surgery Database v3.3. Available at: https://www.sts.org/sites/default/files/documents/Congenital_V3_ 3_TrainingManual_December2018.pdf. Accessed March 24, 2019.

18. Hornik CP, Collins RT II, Jaquiss RD, Jacobs JP, Jacobs ML, Pasquali SK, et al. Adverse cardiac events in children with Williams syndrome undergoing cardiovascular surgery: an analysis of the Society of Thoracic Surgeons Congenital Heart Surgery Database. J Thorac Cardiovasc Surg. 2015;149:1516-22.

19. Hawn MT, Graham LA, Richman JS, Itani KM, Henderson WG, Maddox TM. Risk of major adverse cardiac events following noncardiac surgery in patients with coronary stents. JAMA. 2013;310:1462-72.

20. Mastropietro CW, Benneyworth BD, Turrentine M, Wallace AS, Hornik CP, Jacobs JP, et al. Tracheostomy after operations for congenital heart disease: an analysis of the Society of Thoracic Surgeons Congenital Heart Surgery Database. Ann Thorac Surg. 2016;101:2285-92.

21. Mahle WT, Newburger JW, Matherne GP, Smith FC, Hoke TR, Koppel R, et al. Role of pulse oximetry in examining newborns for congenital heart disease: a scientific statement from the AHA and AAP. Pediatrics. 2009;124:823-36.

22. Mahle WT, Martin GR, Beekman RH III, Morrow WR, Section on Cardiology and Cardiac Surgery Executive Committee. Endorsement of Health and Human Services recommendation for pulse oximetry screening for critical congenital heart disease. Pediatrics. 2012;129:190-2.

23. Abouk R, Grosse SD, Ailes EC, Oster ME. Association of US state implementation of newborn screening policies for critical congenital heart disease with early infant cardiac deaths. JAMA. 2017;318:2111-8.

24. Kemper AR, Lam WKK, Bocchini JA Jr. The success of state newborn screening policies for critical congenital heart disease. JAMA. 2017;318:2087-8.

25. Lightfoot M, Hough P, Hudak A, Gordon M, Barker S, Meeder R, et al. Audit of pulse oximetry screening for critical congenital heart disease (CCHD) in newborns. Paediatr Child Health. 2017;22:305-6.

26. Epting CL, McBride ME, Wald EL, Costello JM. Pathophysiology of postoperative low cardiac output syndrome. Curr Vasc Pharmacol. 2016;14: 14-23.

27. Bronicki RA, Hall M. Cardiopulmonary bypass-induced inflammatory response: pathophysiology and treatment. Pediatr Crit Care Med. 2016;17: S272-8.

28. Rajasinghe HA, McElhinney DB, Reddy VM, Mora BN, Hanley FL. Long-term follow-up of truncus arteriosus repaired in infancy: a twenty-year experience. $J$ Thorac Cardiovasc Surg. 1997;113:869-78.

29. Perron J, Moran AM, Gauvreau K, del Nido PJ, Mayer JE Jr, Jonas RA. Valved homograft conduit repair of the right heart in early infancy. Ann Thorac Surg. 1999:68:542-8.

30. Vohra HA, Whistance RN, Chia AX, Janusauskas V, Nikolaidis N, Roubelakis A, et al. Long-term follow-up after primary complete repair of common arterial trunk with homograft: a 40-year experience. J Thorac Cardiovasc Surg. 2010; 140:325-9.

31. Poynter JA, Eghtesady P, McCrindle BW, Walters HW, Kirshbom PM, Blackstone EH, et al. Association of pulmonary conduit type and size with durability in infants and young children. Ann Thorac Surg. 2013;96:1695-702.

32. Danton MH, Barron DJ, Stumper O, Wright JG, De Giovannni J, Silove ED, et al. Repair of truncus arteriosus: a considered approach to right ventricular outflow tract reconstruction. Eur J Cardiothorac Surg. 2001;20:95-103.

33. Chen JM, Glickstein JS, Davies RR, Mercando ML, Hellenbrand WE, Mosca RS, et al. The effect of repair technique on postoperative right-sided obstruction in patients with truncus arteriosus. J Thorac Cardiovasc Surg. 2005;129:559-68.

34. Nemoto S, Ozawa H, Sasaki T, Katsumata T, Kishi K, Okumura K, et al. Repair of persistent truncus arteriosus without a conduit: sleeve resection of the pulmonary trunk from the aorta and direct right ventricle-pulmonary artery anastomosis. Eur J Cardiothorac Surg. 2011;40:563-8.
35. Louis C, Swartz MF, Simon BV, Cholette JM, Atallah-Yunes N, Wang H, et al Modified repair of type I and II truncus arteriosus limits early right ventricular outflow tract re-operation. Semin Thorac Cardiovasc Surg. 2018;30:199-204.

Key Words: truncus arteriosus, cardiopulmonary bypass, risk factors, cardiopulmonary, resuscitation, extracorporeal membrane oxygenation, body surface area, postoperative care, early diagnosis

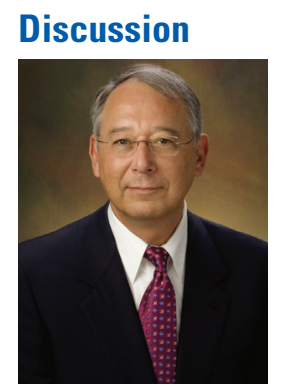

Dr Thomas L. Spray (Philadelphia, $P a)$. These authors have collected extensive preoperative, intraoperative, and postoperative data on 216 neonates and infants with truncus over a 7-year period at 15 centers in the United States to evaluate the potential risk factors for major adverse cardiac events after repair. Twenty-one percent of the population had a major event and 16 patients died, or $7 \%$ of the total, $10 \%$ required $\mathrm{ECMO}$, and $12 \%$ cardiopulmonary resuscitation in the postoperative period. The data from these 15 centers is remarkably similar to the collected data from the STS Congenital Heart Surgery Database in terms of mortality and need for ECMO support, suggesting that the 15 centers, which in fact represent a range from small- to large-volume programs, accurately reflect the overall patient population that does undergo this procedure. The authors found there was a trend suggesting patients who were discharged from the neonatal unit with medical management and later repair had a worse outcome than those who underwent surgical repair earlier and that longer duration of cardiopulmonary bypass of over 150 minutes and the use of larger RV-PA conduits are associated with adverse events.

It has been recognized I think for many years that truncus arteriosus is an unstable lesion and that cardiovascular collapse can occur at any time as pulmonary resistance drops, and therefore most centers consider truncus to be a condition that would require urgent newborn surgery at the same hospitalization, and the authors' results tend to confirm the desirability of early surgery.

Longer cardiopulmonary bypass time was associated with a worse outcome in almost all congenital heart lesions. It is notable that the median bypass time difference in those patients with major adverse events compared with those without events was only approximately 20 minutes. However, the range of bypass times was significantly wider in the patients with adverse events, potentially reflecting more complex operations or difficulties with the repair.

With the small number of patients in this series that actually had adverse events or died, it would be useful to see if there were any specific characteristics of those patients who 
required prolonged bypass times in terms of their operative procedure. Maybe you could tease out some of those effects of longer bypass time and whether it was actually the more complex repair that caused a longer time.

You speculate that larger conduit size might cause adverse events from larger ventriculotomies and potential sternal compression. However, it is noted that over 50\% of the patients had elective open sternums at the end of the procedure and therefore it's not really clear that conduit size or sternal closure per se would be associated with adverse events because most of the chests were open at that time. In addition, the difference in ventriculotomy size between a 12- and 10-mm conduit is relatively small. The tachyarrhythmias also tended to occur more commonly in patients with larger conduits. I would suggest that perhaps rather than ventriculotomy size or ventriculotomy issues and RV dysfunction that larger conduits tend to represent essentially an aneurysm of the right ventricle where the total stroke volume might barely fill the proximal conduit, and tachycardia might be a result of inefficiency of right ventricular outflow.

In addition, it has been our experience that the most common complication after repair of truncus is kinking of the branch pulmonary arteries with either stretch of the right pulmonary artery or stenosis of the left pulmonary artery because the pulsatility of the conduit and the size mismatch between the conduit and the pulmonary branches can cause kinking of the pulmonary vessels. Relative conduit stenosis can affect RV function and overall cardiac output. And with the small number of mortalities in this series, only 16 , I wonder if you could comment on whether the actual causes of death were identified in the patients who did not survive their major cardiac events and whether there was echocardiographic evidence of any kind of technical issue at the completion of operation in those patients who ultimately went on to have adverse events or mortality.

You collected data on many variables preoperatively, intraoperatively, and postoperatively, but I saw no evidence of an assessment of the intraoperative echo and a correlation with major adverse events postoperatively, nor inotropic use postoperatively and other indicators of poor cardiac output. I wonder if you could comment on that.

Perhaps a more aggressive examination of the pulmonary outflow tract in patients who are not responding as expected after cardiac repair would identify some patients who might have revision of their surgical repair with potential improvement of their outcome and reversing of their adverse event.

Although you noted in your manuscript that conduit type was not directly associated with adverse outcome, it is notable that use of the Contegra conduit, as you mentioned, was much more common in those with adverse events. Because the Contegra conduit's smaller sizes seem to have a size $>50 \mathrm{~mm}^{2}$ body surface area in all but the very large potential recipients, would you recommend that the Contegra conduit be discontinued in use for truncus arteriosus repair and femoral vein or other homograft conduits be preferentially used? Also, would you recommend maybe that we even abandon the use of conduits in the current era of primary repair and go back to the original truncus repair as described by Barbero-Marcial and others with direct connection of the right ventricle to the pulmonary arteries.

It is clear that truncus repair continues to carry a remarkably high mortality for what is really a simple operation, VSD closure and a conduit. It is surprising that if you look at the overall mortality, and even in the STS database, it can range as high as $10 \%$ for what is a fairly simple lesion.

Although I agree that conduit size is very likely to be a significant factor in hemodynamics after repair, did you analyze the mortalities carefully to see if there were any other patterns in terms of residual cardiac lesions or postoperative signs that might suggest a higher risk for a poor outcome? It is interesting that you had a lower incidence of major adverse events in patients with DiGeorge syndrome, which is contrary to what we would otherwise generally expect.

I congratulate you on undertaking a study with data collection over multiple centers and adding to the literature on what still remains a relatively high-risk cardiac procedure despite standardized surgical approaches over the past 30 years.

You didn't include echo data, I noticed, in your analysis, and I would assume that in these centers all patients underwent an echocardiogram at the end of the cardiac procedure.

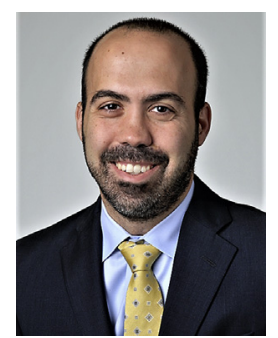

Dr Christopher W. Mastropietro (Indianapolis, Ind). Thank you for the wonderful summary and insightful questions. We did have postoperative echocardiographic data. We have actually a lot of data, more than I could actually present in this session. We looked at ventricular function, valvular regurgitation, valvular stenosis, and the presence or absence of an atrial septal defect or PFO. We really found no clear association between echocardiographic data other than if you had severely depressed ventricular function-that was typically associated with one of these events. But typically those patients were the ones that were on ECMO support.

As far as patterns, we did identify a few interesting patterns. One pattern is that we had a handful of patients who had truncal valve repairs and replacements during the same operation. Those patients who had a valve repair attempt first, then came off pump but the surgeons didn't like the way it looked and the patients weren't doing well, went back on pump, then underwent replacement-these patients had extremely long bypass runs and ended up on ECMO, and I think only 1 of those patients survived, as 
opposed to the patients who had very ugly valves that the surgeons just replaced without a previous attempt at repair-these patients had much shorter bypass runs, did not come off bypass on ECMO, and all of those patients survived.

As I wrote in the manuscript, 12 patients were actually sent home with the diagnosis of truncus arteriosus, with a plan to be managed medically and told to come back at a later date for surgery. Of these patients, 7 were readmitted before their surgical day in severe respiratory failure, 1 of them went on ECMO, and 1 of them developed severe necrotizing enterocolitis. So those patients went into these operations in a rough state and obviously came out in a rough state.

There were definitely a few of the incidents of CPR where the triggering events led to either ECPR or death, and there were just a handful of patients that came out on ECMO and just were not able-it was just one problem after anotherto be liberated from ECMO and were ultimately withdrawn from support. So that's my synopsis of some of the insight into some of the reasons why they died.

As far as your comments on conduit size, I believe you asked if the Contegra should not be used in favor of the smaller conduits. I don't think we can say that, but I definitely think if you have a sick patient who is going into the operation in a less than optimal state, you probably should pay a little bit more attention to conduit size, because that might be 1 extra factor that might push that kid over into requiring ECMO or having an adverse event.

I know I didn't answer all of your questions. I think we will start with that and you can draw out whatever I didn't address.

Dr Spray. I think you addressed them fine. I think you are on to something with conduit size. I do think conduit size and larger sizes is more of a problem in terms of pulmonary artery reconstruction, not so much ventriculotomy, and then the question is, what is the RV pressure at the end of the operation. And if you have tricuspid regurgitation and you have significant RV hypertension, sometimes that's related to pulmonary artery kinking rather than RV failure per se, then that evolved into RV failure, ECMO support, but then sometimes subsequent improvement and you can come off ECMO.

You didn't really say what categories of patients with adverse events went on to die as opposed to those who went on to recover, and the ones who recovered, was there something unique about them that made them recover compared with the others?
Dr Mastropietro. I don't think we really got that granular with the data as far as looking to see which patients with the larger conduits actually made it through their ECMO run or made it through their episode of CPR and actually did not die and what happened to them down the road, something I can easily look back at. We have all the descriptive data.

And I agree with you completely. Your speculation is obviously going to be better than mine as far as why the larger conduit sizes might be associated with these events. I think your insight is great and it is stuff I wish I would have wrote in the manuscript.

Dr Spray. People went to conduit repair for truncus because the perception was that the patients had more instability when you didn't have a pulmonary valve in the RV outflow tract at the time of repair and that pulmonary hypertension would be less well tolerated by the right ventricle, and that was really the primary reason to use conduits in the initial repair. One wonders if in the current era whether that's really true anymore and whether we might consider going back to nonconduit reconstruction as a way of avoiding some of these problems.

But I think it is a very interesting study. Thank you.

Dr Mastropietro. Thank you.

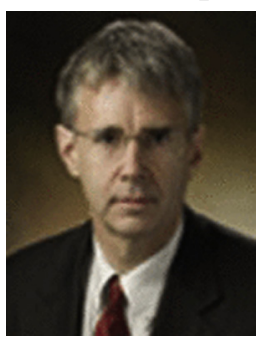

Dr J. William Gaynor (Philadelphia, $\mathrm{Pa}$ ). One brief question. Was the use of conduits uniform across the centers or was it only a few that used Contegra? You looked at center volume, but in your analyses did you include a center variable in the univariate and multivariate analysis, did you adjust for institution across those, because if Contegra is only used at a few institutions, it could be a marker for an institutional variation.

Dr Mastropietro. For sure. We actually used a random effect for center, and we didn't actually put center volume into the model.

Dr Gaynor. Not center volume but center.

Dr Mastropietro. Yes, center as a variable in and of itself. And the conduit type actually varied much more with surgeon and not necessarily with center. There was I think only 1 center that universally used the same conduit for all the operations. Most centers seemed to have multiple conduits.

Dr Gaynor. Was the Contegra used at all?

Dr Mastropietro. I think the Contegra was not used at all centers. I think it was used at 4 or 5 of the 15 . The larger centers seemed to use the Contegra more than the smaller ones. 


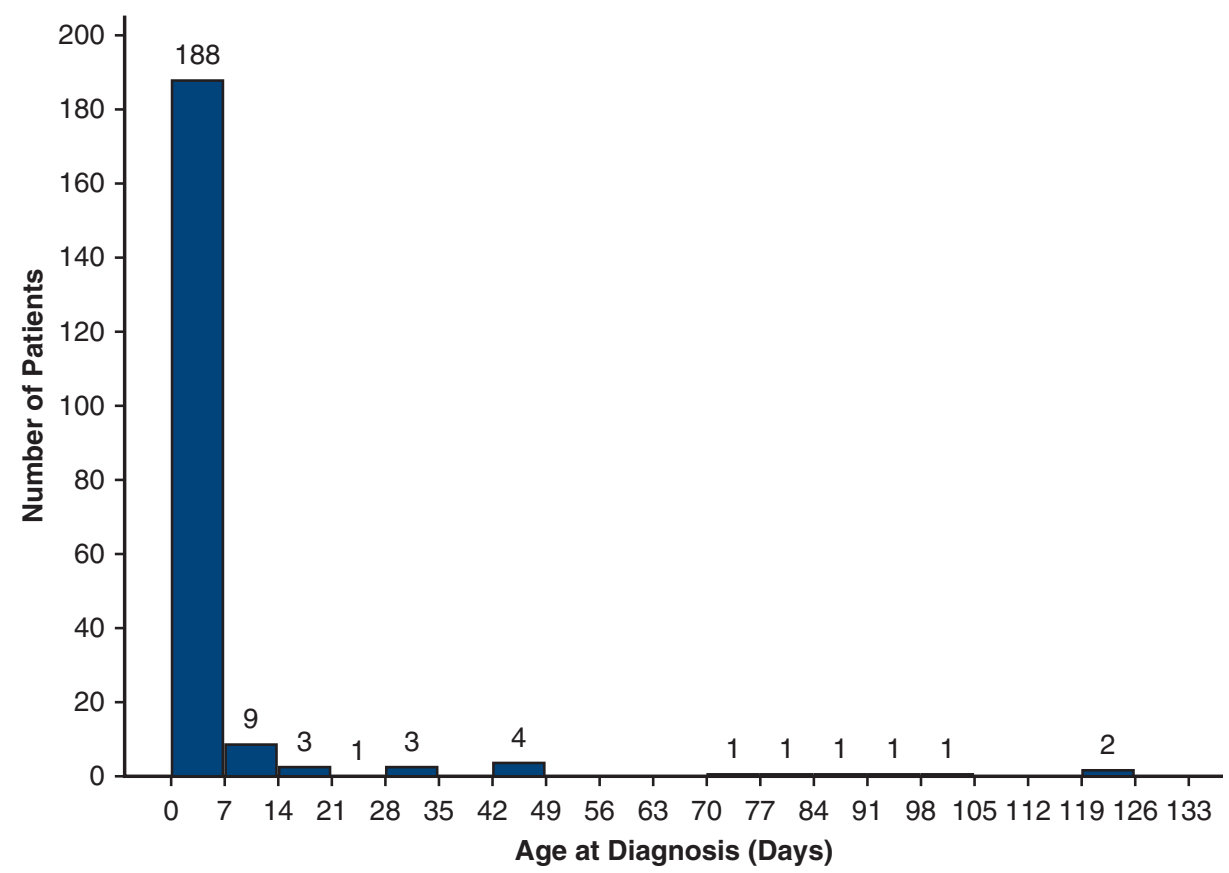

FIGURE E1. Histogram showing the variation in age at diagnosis of patients with truncus arteriosus included in the study. Most patients (n $=188 ; 87 \%)$ were prenatally diagnosed or diagnosed within the first week of life, whereas 14 patients $(6 \%)$ were diagnosed outside the neonatal period ( $>30$ days), which includes an outlier not represented in the histogram - a child who was adopted from outside the United States with a presumed diagnosis of tetralogy of Fallot but was found to have truncus arteriosus upon evaluation on day of life 1275 (3.5 years). 


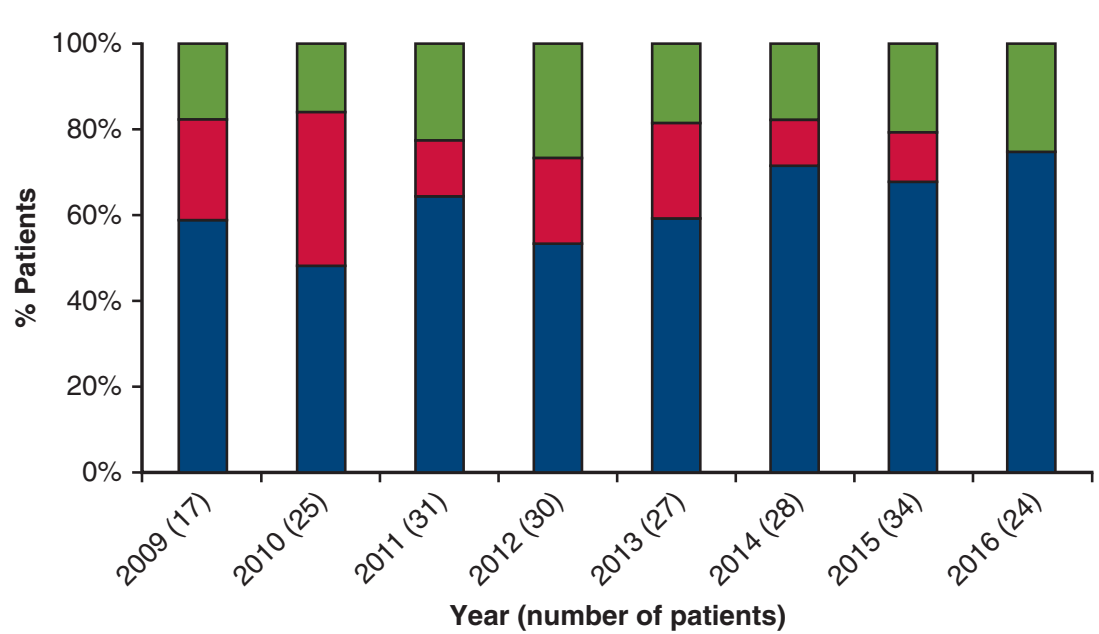

FIGURE E2. Trends in the diagnosis of truncus arteriosus over time. The percentage of patients diagnosed with truncus arteriosus prenatally (blue bars), postnatally but before discharge from the nursery (red bars), and postnatally after discharge from the nursery (green bars). The variations in the percentage of patients diagnosed prenatally and patients diagnosed after discharge from the nursery over the duration of the study period were not statistically significant $(P=.48$ and $P=.98$, respectively). 


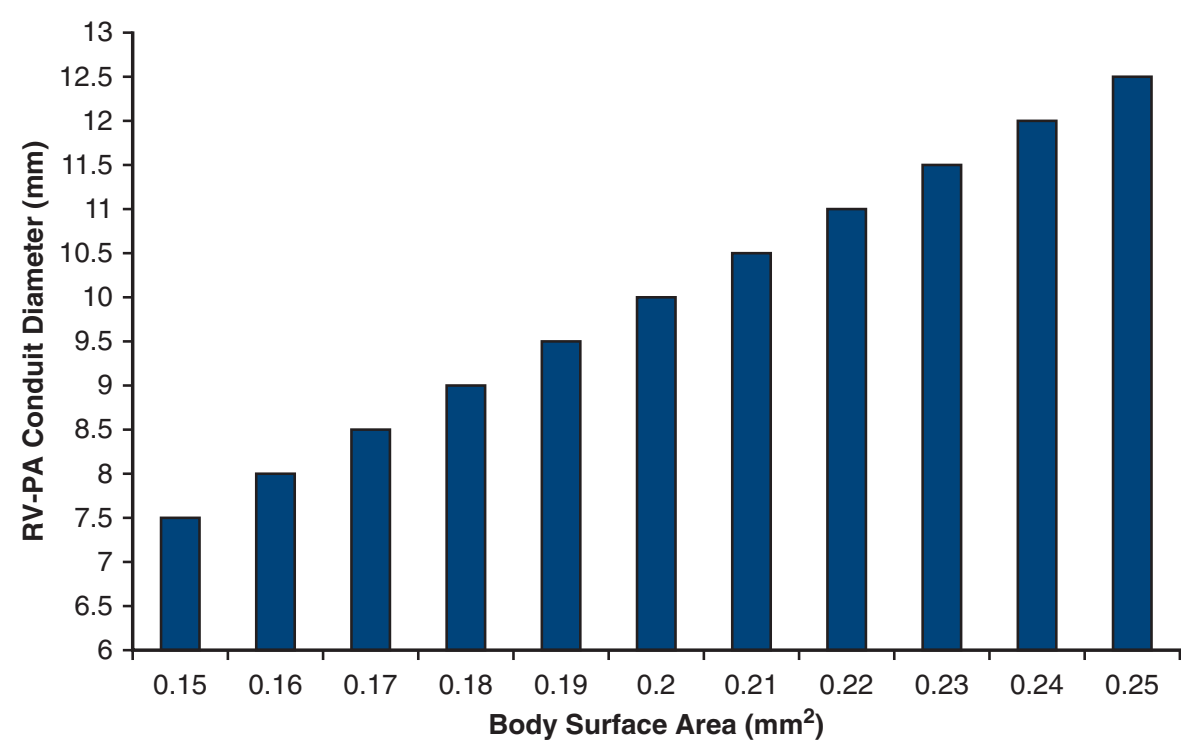

FIGURE E3. Absolute right ventricle-to-pulmonary artery $(R V-P A)$ conduit diameters for patients with body surface areas between 0.15 and $0.25 \mathrm{~mm}{ }^{2}$ (10th percentile to 90th percentile of study population) that will result in diameters indexed to body surface area up to $50 \mathrm{~mm} / \mathrm{m}^{2}$. RV-PA conduit diameters above the blue bars at each body surface area might increase the risk of major adverse cardiovascular events after repair of truncus arteriosus.

TABLE E1. Collaborative Research in Pediatric Cardiac Intensive Care (CoRe-PCIC) participating institutions

- Riley Hospital for Children, Indianapolis, Indiana

- Cleveland Clinic, Cleveland, Ohio

- Children's Hospital of Michigan, Detroit, Michigan

- Morgan Stanley Children's Hospital of New York, New York, New York

- Cohen Children's Medical Center, New Hyde Park, New York

- Medical University of South Carolina Children's Hospital, Charleston, South Carolina

- Children's National Health System, Washington, DC

- Arnold Palmer Hospital for Children, Orlando, Florida

- Seattle Children's Hospital, Seattle, Washington

- Ann \& Robert H. Lurie Children's Hospital of Chicago, Illinois

- University of Iowa Stead Family Children's Hospital, Iowa City, Iowa

- Cincinnati Children's Hospital Medical Center, Cincinnati, Ohio

- Primary Children's Hospital, Salt Lake City, Utah

- University of Michigan C.S. Mott Children's Hospital, Ann Arbor, Michigan

- American Family Hospital, Madison, Wisconsin 


\section{TABLE E2. Data collection and definitions}

\section{Preoperative data}

- Age, sex, race, ethnicity, and anthropometric data

- Estimated gestational age at birth

- Prematurity: less than 37 weeks' gestation

- Presence of genetic anomalies or noncardiac anatomic anomalies

- Age and setting of diagnosis (ie, prenatal diagnosis, diagnosis after birth but before discharge from the nursery, or diagnosis after discharge from the nursery)

- Type of truncus arteriosus (Van Praagh) ${ }^{16}$

Type A1: identifiable main pulmonary artery segment

Type A2: branch pulmonary arteries come off separately from posterior aorta

Type A3: pulmonary blood flow to one lung is supplied by ductal or collateral blood flow

- Preoperative echocardiography data: ventricular function, truncal valve anatomy, degree of stenosis or regurgitation

- Need for preoperative mechanical ventilation or inotropic infusion(s)

- Preoperative shock: $\mathrm{pH}<7.2$ or lactate $>4 \mathrm{mg} / \mathrm{dL}$, as defined by The Society of Thoracic Surgeons-Congenital Heart Surgery Database ${ }^{17}$

- Preoperative infection or necrotizing enterocolitis

- Stroke or seizure: patients with clinical or subclinical seizure activity were recorded as having seizures

- Pulmonary artery banding before surgical repair

Operative data

- Age, weight, height, and body surface area at surgery

- Duration of cardiopulmonary bypass and aortic cross clamping

- Use of deep hypothermic circulatory arrest

- Lowest intraoperative temperature

- Use of intraoperative systemic corticosteroids, modified ultrafiltration, or factor VIIa

- Right ventricle-to-pulmonary artery conduit size and type

- Truncal valve intervention (eg, repair or replacement)

Postoperative data

- Use of delayed sternal closure

- Use of extracorporeal membrane oxygenation

- Use of cardiopulmonary resuscitation

- Use of inhaled nitric oxide therapy

- Occurrence of postoperative arrhythmia

- Occurrence of uplanned cardiac catheterization or operation

- Postoperative infection (includes necrotizing enterocolitis)

- Postoperative stroke or seizure

- Occurrence of postoperative respiratory complications: extubation failure, chylothorax, paralyzed diaphragm, vocal cord paralysis, or tracheostomy

Outcome data

- Initial and total duration of postoperative mechanical ventilation

- Duration of intensive care unit and hospital length of stay

- Operative mortality ${ }^{17}$

Mortality occurring before discharge from the hospital where the index cardiac operation took place or any secondary acute care facility

Any out-of-hospital deaths occurring within 30 days of the index cardiac operation,

Any deaths occurring in a secondary chronic care facility (or rehabilitation facility) within 180 days after the index cardiac operation
TABLE E3. Postoperative complications after repair of truncus arteriosus

\begin{tabular}{|c|c|}
\hline Variable & All patients $(\mathrm{N}=\mathbf{2 1 6})$ \\
\hline Delayed sternal closure, planned & $119(55 \%)$ \\
\hline Delayed sternal closure, unplanned & $7(3 \%)$ \\
\hline CPR & $26(12 \%)$ \\
\hline ECMO & $22(10 \%)$ \\
\hline Initiated in OR & 13 \\
\hline Initiated in ICU & 9 \\
\hline Inhaled nitric oxide use & $102(47 \%)$ \\
\hline Initiated in OR & 69 \\
\hline Initiated in ICU & 33 \\
\hline Tachyarrhythmia & $63(29 \%)$ \\
\hline Treated with medication & 45 \\
\hline Treated with temporary pacing wires & 18 \\
\hline Bradyarrhythmia & $7(3 \%)$ \\
\hline Treated with medication & 1 \\
\hline Treated with temporary pacing wires & 6 \\
\hline Unplanned cardiac catheterization & $25(12 \%)$ \\
\hline Unplanned reoperation for bleeding & $37(17 \%)$ \\
\hline Unplanned reoperation not for bleeding* & $17(8 \%)$ \\
\hline Truncal valve repair/replacement & 6 \\
\hline Residual VSD closure & 5 \\
\hline Coronary artery revision & 3 \\
\hline Pulmonary arterioplasty & 3 \\
\hline RV-PA conduit revision & 3 \\
\hline Aortopexy & 2 \\
\hline Other & 9 \\
\hline Infection $†$ & $42(19 \%)$ \\
\hline Sepsis/bacteremia & 9 \\
\hline Endocarditis & 2 \\
\hline Pneumonia/tracheitis & 16 \\
\hline Urinary tract infection & 5 \\
\hline Wound infection/dehiscence & 12 \\
\hline Mediastinitis & 3 \\
\hline Other & 4 \\
\hline Necrotizing enterocolitis & $10(5 \%)$ \\
\hline Extubation failure & $22(10 \%)$ \\
\hline Chylothorax & $22(10 \%)$ \\
\hline Paralyzed diaphragm & $6(3 \%)$ \\
\hline Vocal cord paresis & $2(1 \%)$ \\
\hline Tracheostomy & $11(5 \%)$ \\
\hline Seizures & $17(8 \%)$ \\
\hline Stroke & $12(6 \%)$ \\
\hline Operative mortality & $15(7 \%)$ \\
\hline
\end{tabular}

$C P R$, Cardiopulmonary resuscitation; $E C M O$, extracorporeal membrane oxygenation; $O R$, operating room; $I C U$, intensive care unit; $V S D$, ventricular septal defect; $R V$-PA, right ventricle-to-pulmonary artery. *Seventeen patients required 33 cardiothoracic reoperations for an indication other than bleeding/hemorrhage. †Forty-two patients were diagnosed with 51 postoperative infections. 